\title{
The Strategic Use of Evidence in UK E-Cigarettes Policy Debates
}

Benjamin Hawkins and Stefanie Ettelt (LSHTM)

[Evidence and Policy- Accepted final]

\section{Abstract}

Background

Current debates on e-cigarette policy in the UK are both highly acrimonious and are framed in terms of evidence-based policy-making.

\section{Aims and objectives}

The article aims to understand the use of evidence in policy-making in the context of both political controversy and limited policy-relevant evidence via a case study of UK e-cigarette debates.

Methods

The study draws on a series of semi-structured interviews with policy actors to examine their positions on e-cigarette policy process and their use of evidence to support this.

Findings

Policy actors articulate a strong commitment to evidence-based policy-making and claim that their positions are evidence based. Some actors also claim emerging consensus around their positon as a rhetorical tool in the debate. Respondents argued that actors adopting opposing policy positions fail to follow the evidence-base. This is attributed to a lack understanding or disregard for the relevant evidence for political or ideological reasons.

\section{Discussion}

Respondents adhere to a rationalist understanding of policy-making in which policy disputes can be settled by recourse to 'the evidence.' Interpretative policy analysis suggests that multiple legitimate framings of policy issues, supported by different bodies of evidence are possible. Policy differences are thus not due to bad faith but to policy actors framing the issue at stake in different terms and thus advocating different policy responses.

\section{Conclusions}

Process of 'frame reflection' may help to overcome the acrimony of current policy leading to more effective engagement by public health actors in the e-cigarettes policy debates. 


\section{Introduction}

As a new technology, electronic cigarettes (e-cigarettes) pose a regulatory challenge to governments seeking to balance the potential health benefits for existing smokers against their implications for the wider public health. National governments have taken very different approaches to these new products, ranging from outright bans on their sale and/or use (e.g. in Australia) to their regulation as consumer products, tobacco products or medical devices. Within the European Union (EU), e-cigarettes were covered by the 2014 tobacco products directive (TPD; 2014/40/EU), which set out a dual approach to regulation which allows e-cigarettes to be regulated either as tobacco products or as licenced medical devices.

The United Kingdom (UK) has emerged as a key market for e-cigarettes and as a test ground for the main regulatory debates surrounding e-cigarettes. The reasons for this are manifold. The UK has strong tobacco control policies by global and European standards, limiting for example the environments in which it is possible to smoke, and has experienced a decline in smoking prevalence in the last four decades (ASH, 2016). Despite this, around $20 \%$ of the male adult population and $14 \%$ of women continue to smoke; a total of 7.6 million current smokers (ASH, 2016). The global headquarters of some of the world's largest cigarette producers such as British American Tobacco (BAT), which have invested significantly in e-cigarettes and new nicotine technologies, are located in the UK (Tobacco Tactics, 2014). These companies have actively promoted the harm reduction potential of e-cigarettes, whilst continuing to market conventional tobacco products (British American Tobacco, 2013, British American Tobacco, 2014). There is also a long-standing and highly developed network of medical associations (e.g. The British Medical Association and the various Royal Colleges), and non-governmental organisations (NGOs; such as Action on Smoking and Health $[\mathrm{ASH}]$ and the British Heart Foundation), which have been global leaders in anti-smoking campaigns and policy debates. For these reasons, developments in the UK are of strategic importance to both the e-cigarette industry and tobacco control advocates globally.

Whilst health advocates in the UK and elsewhere have, in recent decades, collaborated effectively on various policy issues (Wipfli, 2015, Gneiting, 2015), including the campaign to introduce standardised cigarette packaging, the debates on e-cigarettes has divided both the tobacco control and wider public health communities (Gornall, 2015). In the UK, these tensions came most obviously to the fore following the publication of Public Health England's (PHE) report on the safety of e-cigarettes (McNeill et al., 2015a) and the subsequent criticism of this (McKee and Capewell, 2015a). At the global level, these divisions were evident in two letters sent to WHO Secretary General Margaret Chan setting out very different positions on e-cigarettes, each signed by eminent figures in the field (Abrams et al., 2014, Aktan et al., 2014). Some public health advocates 
have proposed strict regulation of e-cigarettes citing the uncertain health effects and the precautionary principle (see Bush et al., 2016, McKee and Capewell, 2015b). Proponents of 'harm reduction' approaches, meanwhile, have argued that excessive controls on availability, use and marketing may curtail the uptake of these apparently safer products by smokers (see Farsalinos and Le Houezec, 2015, Bauld et al., 2016). The harm reduction approach has been vociferously supported by e-cigarette user groups (such as the New Nicotine Alliance) and e-cigarettes producers, including those controlled by transnational tobacco corporations (British American Tobacco, 2013, British American Tobacco, 2014).

What is most noteworthy is that the claims of actors on both sides of the debates are couched in terms of evidence; both camps cite relevant studies that support their positions, and make wider appeals to an ideal of evidence-based policy-making to which decision-makers should adhere. This is in keeping with both the nature of the issue being debated, and the prominence afforded to evidence use in policy-making in the UK in the last two decades, not least in the area of health policy. However, the calls for evidence-based policies on e-cigarettes pose clear challenges for decision-makers. Despite the commitment of the UK government, and those elsewhere, to evidence-based policy-making, the novelty of these products - and the necessary time lag before long-term epidemiological data, for example, will be available to decision-makers - means only limited policy-relevant evidence is available to guide policy.

It is beyond the scope of the current article to review the emerging literature on e-cigarettes safety and usage patterns (see Grana et al., 2014a, Grana et al., 2014b, Adkison et al., 2013, McNeill et al., 2015a, Kalkhoran and Glantz, 2016) or to pass judgement on the strength of the evidence supporting the positions adopted by different policy actors (defined here as all actors involved in policy debates including lobbyists and advocates seeking to shape policy-making processes as well as politicians and administrators involved in decision-making and implementation). The aim of this article is not to intervene in these highly contentious debates, or to seek to shape regulatory direction taken on e-cigarettes. Our interest is, instead, on the process of evidence use in policymaking via a case study of current UK policy debates on e-cigarettes. In analysing these debates, we seek to understand in greater depth the role of evidence claims by policy actors in this highly divisive policy area. Our primary interest is thus on evidence use rather than e-cigarettes. From a policy studies perspective, the e-cigarette debates offer potentially important insights into the strategic uses of evidence within discourses of evidence-based policy-making. E-cigarettes provide an important case study of the ways in which policy debates on complex issues are conducted in circumstances where there is both limited policy-relevant evidence, and a strong rhetorical commitment of UK policy actors to evidence-based policy-making. These conditions provide a 
powerful incentive for decision-makers and policy advocates to legitimise their policy in terms of its supporting evidence, whilst policy-makers must be seen to be acting in accordance with the prevailing evidence-base.

The article examines the use of evidence by proponents of different regulatory approaches to e-cigarettes, through an examination of the positions they adopt on e-cigarettes' potential public health effects and the justifications they give for these. It draws on a series of semi-structured interviews with key participants in the UK e-cigarette policy debates, an analysis of relevant documents in the public domain and a review of the relevant literature on evidence based policymaking. We identify two broad approaches to the issue within the public health community, which has been widely recognised in previous exchanges in the media and scientific publications (cf. McNeill et al., 2015a, McNeill et al., 2015b, and McKee and Capewell, 2015a, McKee and Capewell, 2015b). We understand that the identification of these two broad positions fails to capture the full range of positions adopted by policy actors on the issue of e-cigarettes, and that the views of actors within these 'camps' may differ internally, but do not seek to map the specific positions adopted by individuals on this subject. Our aims is, instead, to examine evidence claims made in favour of both more permissive and restrictive policy approaches to e-cigarettes within public health. The article builds on our understanding of the role of evidence in the policy process, in the context of a highly controversial policy issue, with strong rhetorical commitment to evidence use and evidence-based policy on both sides of the debate, but an absence of definitive evidence on a number of key policyrelevant issues. It examines why policy debates structured around evidence claims has become so vehement and, in so doing, may begin the process of moving beyond the current impasse within public health.

\section{Methods}

The authors undertook a series of semi-structured interviews with key policy actors in the UK engaged with the issue of e-cigarettes between June and November 2015. Respondents were identified through both purposive and snowball sampling in keeping with established methodological practices in the social sciences (Rubin and Rubin, 2011). We did not undertake interviews with tobacco industry owned or independent e-cigarette producers given the ethical controversies this raises (Hawkins and Cassidy, 2016). We identified initial respondents through a review of relevant policy documents and publications on the issue and through attendance at ecigarette conferences and events (purposive sampling). In the analysis phase, key themes emerging from the documents also informed the identification of 'codes' and themes used to analyse 
interview responses. We conducted a total of nine interviews with relevant actors from government, academia and the NGO sector. Interviewees were contacted initially via email and follow up telephone calls. Potential interviewees were supplied with information sheets and consent forms prior to the interview to allow them to give fully informed consent to participate.

Most interviews $(n=5)$ were conducted jointly by the two authors but two were conducted by the first author and two by the second author individually. Two civil servants, two academics and one NGO approached for interviews declined to participate, reflecting the highly sensitive nature of the policy area. We nevertheless had respondents from all three sectors and those broadly supportive and more cautious about the contribution of e-cigarettes to public health. Interviews were conducted either face-to-face in respondents' offices or via telephone or skype if based outside of London $(n=3)$ and lasted on average around an hour in length. We asked each respondents what they perceived to be the key regulatory issues facing governments in relation to e-cigarettes which require a policy response and to identify the key bodies of research relating to them. We were able to identify respondents' views about what the policy priorities should be for government, their favoured approach to addressing these issues, and their perceptions about the strength of evidence supporting these positions and alternative priorities and approaches. Interviewees were also asked to recommend additional respondents from their knowledge of the field (snowball sampling).

All interviews were voice recorded and transcribed by a third party, subject to a confidentiality agreement. The analysis of the interviews was undertaken by the first author. Transcripts were first read to identify key themes and codes. Key findings and potential codes were discussed with the second author at this stage and further refined, before being used to code the interviews systematically using qualitative data analysis software (NVIVO 10). Respondents were offered anonymity and confidentiality for their responses given the highly politicised nature of the policy debates, although they could elect on the consent form to be identified by their sector or organisation depending on the degree of anonymity sought. Consequently, we report findings and quotations from interviews in this way along with numbers to distinguish each respondent (e.g. NGO 1, Academic 2 etc). In keeping with the consent form, respondents had the right to withdraw from the study at any time, but were not asked to sign off on quotes before their use. Quotes given are designed as illustrative examples of the points made and we have given indications of how widely shared the viewpoints were amongst respondents. We underline, however, that this is a qualitative analysis designed to examine the structure and content of arguments put forward from different (favourable and unfavourable) perspectives on the e-cigarette debates. It is not exhaustive of the variety of multiple, nuanced positons which exist within (and beyond) the two broad camps we identify. No systematic quantitative analysis was undertaken and such an analysis would not be 
statistically meaningful when undertaken on the size of the dataset collected. Instead, we look to understand the contours and dynamics of policy debates from a purely qualitative perspective.

\section{Evidence use in the policy-making process}

There is now a substantive body of scholarship on evidence-based policy-making and the associated literatures on knowledge transfer, exchange and translation (see Oliver et al., 2014, Greenhalgh and Wieringa, 2011, Lavis et al., 2009, Ellen et al., 2014, Majone, 1989). In her seminal article on research utilization, Carol Weiss (1979) identified six different models of research use by decision-makers. Weiss' typology included not only 'knowledge driven' and 'problem solving' models of evidence use, but also the 'political' and 'tactical' uses of research, in which policy-makers use research findings to justify political decisions already taken or to delay policy action. These accounts of evidence use reflect a dialogical and ideas driven models of policy-making (Smith, 2013), in which policy-makers take complex decisions on the basis of multiple competing priorities and sources of knowledge.

Subsequent interventions in the field have further elaborated on the strategic uses of evidence by both decision-makers and policy advocates (Radaelli, 2005, Davoudi, 2006, Boswell, 2009), and the range of different forms of knowledge which may count as legitimate sources of evidence (Majone, 1989, Stevens, 2007, Smith, 2013).

Greenhalgh and Russell (2006: 36) have argued against narrowly rationalist, linear conceptions of evidence use which still predominate in much of the public health literature, defining the policy process as a 'drama' or 'argumentation game' in which policies are enacted. According to this account, evidence use is conceived as 'rhetorical action' designed to persuade and convince decision makers. In addition, different forms of evidence may at different times hold sway in the discursive and dialogical process of decision-making (Greenhalgh and Wieringa, 2011, Parkhurst and Abeysinghe, 2016).

These approaches recognise the fundamentally political nature of the policy process and the existence of multiple bodies of relevant evidence when adopting policies. What are presented as disputes over facts are often actually debates over competing values, ideologies and political priorities (Stone, 1997). Consequently, these are not disputes that can be resolved by recourse to the relevant evidence base; they are political decisions that must be taken in light of the evidence (Hawkins and Parkhurst 2016). What policy actors perceive as the relevant bodies of evidence for resolving a policy dispute will depend on their framing of the policy problem and the values they prioritise. The competing values at stake in policy debates may be mutually exclusive and come into 
direct conflict. In the context of finite resources, governments have to prioritise certain issues and outcomes over others. This has led to a shift in language from evidence based to evidence informed policy-making and the development of process based accounts of decision-making (Hawkins and Parkhurst, 2016).

In this explicitly political and value-centred account of the policy process (Russell et al., 2008, Greenhalgh and Russell, 2009), evidence may be deployed by policy actors to advocate for a particular policy outcome, to set agendas and shape policy debates. This does not mean, however, that 'anything goes': that any document or testimony, regardless of its origin and conditions of production, counts as evidence or that all evidence is of equal quality and relevance. Rather, it represents a rejection of the idea that all evidence can be evaluated against the same criteria or reduced to a single, unified hierarchy amenable to systematic review. Policy-making thus requires a critical engagement with different bodies of policy relevant evidence to determine both their quality and appropriateness for deciding the issue at hand.

The shift from concepts of evidence-based policy-making to the 'good governance' of evidence (Hawkins and Parkhurst 2016), reflects the emergence of 'interpretative policy analysis' in the study of evidence use (Fischer, 2012, Stone, 1989). The shift towards interpretative approaches to policy analysis recognises the importance of language and meaning in the policy process. Framing theory and discourse analysis have emerged as means to conceptualise and examine the construction of meaning between actors in policy debates (Koon et al., 2016). Policy actors seek to frame issues and shape policy discourses in ways amenable to their interests in order to achieve their policy objectives. Policy conflicts thus emerge where competing policy frames come into conflict over policy relevant issues. Rein and Schön (1994) have argued that processes of 'frame reflection' - a form of empathetic reasoning - are crucial to resolving intractable policy dilemmas. Their approach recognises that different policy actors both within, and outside of, government may view the 'same' policy issue through different lenses and on the basis of differing assumptions and competing priorities. The path to resolution of policy controversies is blocked by the fact that different parties are talking about different things even though they are using the same terminology (or 'signifiers') and thus advocate different policy responses. This is of great relevance to the current UK e-cigarette debates in which policy actors are pursuing different policy objectives (and prioritising different values and potential beneficiaries) whilst seeing their disagreements as conflicts over evidence.

Despite the theoretical developments in the field of evidence-informed policy-making set out above, more traditional, rationalist accounts of the evidence to policy process remain highly 
influential in the field of mainstream public health (cf Thamlikitkul, 2006). According to this model, evidence - which is seen to be derived almost exclusively through the application of (natural) scientific methods - should be applied by decision-makers to produce effective responses to policy problems. 'Politics' meanwhile is regarded as a barrier to the effective application of science. Those engaged in knowledge production often perceive a failure of governments to act in areas they know well, and care about greatly, as a failure by policy-makers to identify and follow 'the evidence'. However, their policy objectives cannot be viewed in isolation inform the wider policy context

Adherence to narrow, transactional accounts of evidence use, and the high degree of specialisation of many public health actors, has important consequences for the argument developed below. First, it leads to the veneration of science and evidence as a potential arbiter of policy disputes. This, in turn, leads actors to seek to identify the (single, unitary) evidence base and to seek consensus amongst (legitimate) participants in the scientific debates about the policy solutions this indicates. Taken together, these assumptions find little space for dissent and contestation as in more overtly political conceptions of the policy process introduced above. Since, from this perspective, evidence can resolve policy controversies, disputes must either be the result of a misunderstanding of the evidence by a policy actor (perhaps due to their lack of relevant expertise or qualifications to participate in the debates) or more sinister motives - e.g. being driven ideology versus fact, corruption or capture by vested interests - which leads them to disregard or misrepresent the evidence base. As will be argued below, interpretative approaches to policymaking, and the conceptualisation of evidence use as rhetorical practice, are of vital importance in explaining the structure, content and the vehement nature of UK e-cigarette policy debates.

\section{Reference to Evidence in the UK e-cigarette debates}

Different sections of the public health community, with particular research foci and differing health policy priorities, viewed the issue of e-cigarettes and thus the key objectives for policies in fundamentally different ways. Whilst we do not offer an exhaustive mapping of the different groups and policy positions relevant to the debates, two broad approaches to the issue emerged which are examined here. This reflected the perceptions of the structure of the debates amongst interviewees. As one respondent commented:

I do think there's also been an unhelpful division into for and against, and a tendency for people to be quite aggressive about the stance they've taken, in some cases (Public Health NGO 4) 
The difference between the two groups were seen to reflect the different academic and disciplinary backgrounds of the actors involved:

You know... people who actually work in the field [i.e. tobacco control] primarily are of one view. And then, where the controversy is, is by and large, very high profile public health people who don't actually work in the field. [...] (Academic 2).

Those working (mainly) in the field of smoking cessation and clinical practice, see the 'issue' of e-cigarettes, and the policy priority for government, to be to help current smokers to quit or reduce smoking through the use of e-cigarettes. Their positon is informed by an emphasis on "harm reduction' for current smokers. Consequently, they favour a regulatory approach that will encourage smokers to transition away from cigarettes to e-cigarettes through greater availability and ease of use (including in public spaces where smoking is banned). This includes the ability to market and promote e-cigarettes and to use them in environments in which smoking is prohibited (e.g. public houses and places of work) (Bauld et al., 2016). For the purpose of the current paper we refer to this broad position as the 'harm reduction' position on e-cigarettes.

Against this, those working in the broader field of public health prioritise concerns about the potential population level effects of e-cigarettes. This includes the impact of e-cigarette use and marketing on existing current tobacco control policies such as clean air laws and tobacco advertising bans. They emphasise the uncertain health consequences of e-cigarette use and call for the precautionary principle to be applied (McKee and Capewell, 2015a). Moreover, they are deeply concerned by the now extensive investment in the e-cigarette sector by the tobacco industry and their potential efforts to shape the development of the sector in ways antithetical to public health (Tobacco Tactics, 2014). Here, we refer to this as the 'precautionary' position on e-cigarettes. The two groups see the issues raised by e-cigarettes - the very nature of the policy problem they present - in fundamentally different ways, representing a different type of regulatory challenge and thus requiring a different type of policy response.

Both the 'harm reduction' and 'precautionary' camps identified here are broad characterisations of the positions adopted by policy actors, and the specific positions of individuals within these fields will vary. Nevertheless, there are clear differences between public health actors on this issue in line with the positions set out above. The divisions which have opened up between these groups are noteworthy and, from a public health perspective, problematic in the context of tobacco control, which has been driven forwards in the UK and beyond by the co-ordinated efforts of a unified public health community (Gneiting, 2015, Wipfli, 2015). Furthermore, these divisions occur in the context in which transnational tobacco companies have assumed a key strategic 
position in the e-cigarette market and the attendant policy debates, which has exacerbated these divisions. Given the well-documented history of tobacco industry attempts to intervene in the scientific process and promote allegedly safer products to stymie tobacco control policies (Hurt et al., 2009, Gilmore and Peeters, 2013), the prospect of policy-makers and public health actors engaging with tobacco companies in their capacity as e-cigarette producers has been a source of great controversy.

\section{E-cigarette policies in the UK}

Most aspects of the sale and marketing of electronic cigarettes in the European Union are governed by the 2014 Tobacco Control Directive, which offers a dual route to market for ecigarettes. E-cigarettes sold within the single market must either be licensed as medical devices or adhere to specific criteria set out within the directive. In each case, a product approval is overseen in member states by a designated 'competent authority', such as the Medicines and Healthcare Products Regulatory Agency (MHRA) in the UK. The route to market chosen affects various aspects of the devices, most notably the concentration of nicotine solutions which can be used within them, and the ways in which they can be marketed and advertised. Devices sold as tobacco products can contain liquids with a maximum concentration of $20 \mathrm{mg} / \mathrm{ml}$ of nicotine. Only products licensed as medical devices can make claims about their health effects in marketing materials. The directive also contains a number of requirements for the packaging and warning labels on products and devices are covered by regulations relating to cross border advertising and marketing of tobacco products related to the functioning of the single market.

National governments remain responsible for other areas of regulation without cross border effects including minimum purchase ages for e-cigarettes and rules relating to their use in public places. In the UK, legislation was passed in October 2015 to ban the sale of e-cigarettes to those under 18 years of age, bringing their conditions of sale into line with tobacco products. The UK government in Westminster, and devolved administrations in Scotland, Wales and Northern Ireland have so far decided against extending clean air legislation to include e-cigarettes, although private companies (e.g. public houses and restaurants) and other bodies (such as Transport for London and train operating companies) have taken unilateral action to ban the use of e-cigarettes on their premises. Responsibility for public health in England is devolved to local authorities, with PHE established as an executive agency of the Department of Health in 2013 to support the achievement of high levels of public health and a reduction of health inequalities. Its remit includes the commissioning and production of research on key public health topics, information sharing with 
local authorities and reporting to different government agencies. PHE had identified e-cigarettes as a priority issue commissioning a series of reports on the topic between 2014 and 2015 (McNeill et al., 2015a, Britton and Bogdanovica, 2014, Bauld et al., 2014).

\section{Commitment to evidence-based policy-making and claims to use evidence}

Despite the limited evidence base on e-cigarettes, evidence claims were at the heart of policy debates in the UK. Most obviously, evidence emerged as a source of legitimacy for the policy positions adopted on the issue. Every respondent $(n=9)$, regardless of the types of organisation they represented or the position they adopted on the issue at hand, supported the principle of evidence use in policy-making and claimed to be led by the evidence in developing their positions on the issue. For example, a representative of a health NGO was asked how their organisation developed its position on e-cigarettes:

So, for me, I think following the evidence and trying to be fleet of foot enough to move as the evidence changes or becomes clearer is important. (Public Health NGO 1).

All respondents were confident that the available evidence supported their position. At the same time, some respondents criticised other policy actors for failing to follow the evidence base. As one researcher in the field commented:

So, when we have public health scientists who are supposed to be trusted individuals, or public health bodies that are, for whatever reason, [...] not interpreting the science correctly, and are using double standards... you know, if we take, for example, the discussion over plain packaging, which I fully support, or the evidence relating to e-cigarettes [...], you know, it's very interesting seeing people applying really different standards of evidence for what they are willing to believe (Academic 2).

Thus, whilst there is a clearly identified need for policy solutions to be determined by the evidence, participants within the policy debates perceive their own interpretation of the evidence, and standards of evidence evaluation, as well as the regulatory agenda which flows from this, to be the right one. From this perspective, disagreements result from the failure (or unwillingness) of other actors to 'correctly' identify and interpret the relevant evidence base.

The acrimony of the disagreements over the interpretations of evidence, and the terms in which they are couched, are worthy of further examination. That respondents claimed to be guided by a dispassionate assessment of the relevant evidence, whilst criticising others for failing to do the 
same, is indicative of the long shadow cast over public health debates by narrowly rationalist models of evidence-based policy-making. These approaches fail to recognise the multiple ways in which policies can be framed and thus the different relevant bodies of evidence, which can be brought to bear on policy debates. The charge that opponents have failed to heed, or have mistakenly interpreted, the evidence may thus be wide of the mark. Instead, these policy actors may simply have framed the policy problem in different terms, and thus identified different bodies of policy relevant evidence, which relate to this framing. To put it differently, policy actors in other camps are being accused of coming to the 'wrong' conclusions when, in fact, they are asking the 'wrong' question, or identifying the 'wrong' policy problem.

If e-cigarettes are viewed principally as a harm reduction tool, the policy regime to be advocated is one which maximises their potential to serve this purpose. From this perspective, the most relevant evidence will be studies of their toxicity compared to cigarettes and their effectiveness as quit aids under different conditions and for different types of smokers. In contrast, actors on the other side of the argument may see the key policy issue to be the effect of e-cigarettes on existing tobacco control policies such as advertising restrictions and clean air legislation and will thus highlight related bodies of evidence to inform policy decisions. As such, actors' claims to objectivity, and thus authority, through recourse to evidence fail to capture the politics of problem definition. Respondents' claims to follow the evidence underline the rhetorical power of discourses of evidence-based policy-making. It reflects also a particular conception of the scientific and policymaking processes in which knowledge and policy problems are unambiguous and in which solutions to the latter can be effectively derived from the former.

\section{Perceptions of policy relevant evidence}

Respondents agreed to differing degrees that the evidence base in these areas was incomplete due the novelty of e-cigarettes as a technology and vaping as an activity, and that additional research was needed to inform their positions on key issues.

The absence of definitive evidence on key policy issues was cited as an explanation for the controversy which has emerged within the public health field. As one NGO actor commented:

I think when the debate has got really ferocious, it's because we've reached the limits of our evidence, and we have to make a decision, or we have to say something when we're not comfortable (Public Health NGO 2). 
The novelty of the devices, and the significant time lag before a sufficiently large body of definitive studies of the health impacts of long-term, real world usage would be available, was highlighted as a key issue by another UK health NGO when asked to identify gaps in the current evidence base:

Their long term impact. Obviously that's the big one. Evidence of harm to bystanders or second hand vapour or third hand vapour has even been floating about [...]. But obviously the long term studies, the multiple studies are what we need. But for them it will take a long time to see that stuff on there. So, you just have to go on the assumption of risk and that's quite difficult when you've got people obviously advocating a precautionary risk (Public Health NGO 3).

Here, the key issue of risk, and how we should evaluate it in light of existing research evidence, comes to the fore. Very different approaches are taken by different actors to the status of the existing evidence. Whilst the respondent above argued that the existing evidence base represented an absence of evidence of risk - and thus a limited justification for regulation - (s)he acknowledges that others saw this uncertainty as requiring more extensive intervention on the basis of the precautionary principle. Other respondents, however, felt that open debate about the evidencebase was being undermined because of the divisions which had emerged. As one academic commented, some actors 'feel even acknowledging the scientific uncertainty is in some way a concession and is letting down their colleagues. We've drifted off from science to stakeholders' (Academic 1).

\section{Claims to consensus}

Whilst most respondents identified deficiencies in the existing evidence on e-cigarettes, some respondents claimed that there was an emerging consensus on the status of the evidence base. Consensus is a powerful concept both in the context of scientific debates and in forming policy coalitions. In mainstream, rationalist epistemologies, the concept of consensus closely approximates that of 'truth' (or our current version of truth). Policy-makers meanwhile desire certainty, often at the expense of nuance, and thus may be moved to action by the unified voice of relevant actors within the sector. This has been reflected in the story of tobacco control and the ability of advocates to act in concert to affect policy change (Wipfli, 2015, Gneiting, 2015). Thus the ability to reach consensus on e-cigarettes - on their desirability and effects, and how they should be regulated would represent a decisive juncture in the relevant scientific and policy debates. 
Much of the effort to build this consensus on e-cigarettes revolves around the activities of PHE and the reports and evidence reviews on e-cigarettes, which they have commissioned. Indeed, as a government official, developing consensus amongst public health actors on e-cigarettes is a key objective of their work:

So at the moment with electronic cigarettes [...], we have a stated ambition which is to build an evidence-based consensus and we have a programme of working with partners quite diversely to achieve that (Official 1 ).

Elsewhere, the same respondent continued:

That's why we were in a position in October when all the key organisations were able to come together and say actually we think [organisation] are right, because we'd been talking for years. And yes, there were other people who weren't involved in that discussion for years, who had either not been invited or just weren't interested or had chosen not to be part of it, they were outside that consensus and they made a lot of noise at the consensus. But it didn't really influence the consensus. So yes, [...] we've got to bring the family around the kitchen table and sort it out. And that's what we are trying to do with, you know, given the controversy, with some degree of success. (Official 1).

From this perspective it seems that the consensus identified is limited to those actors involved in the process of dialogue identified above but excludes other actors not involved in this process who remained 'outside the consensus'. It also reflects an understanding that positions on e-cigarettes have emerged in the context, and perhaps as an extension of, debates in other areas, which had led to a consensus being formed around common objectives in harm reduction, especially in relation to illegal drugs. However, there is also acknowledgement that this 'consensus' is not shared by all actors. In addition, it appears the consensus identified is specific to the UK:

I mean we have two very different consensuses in the UK and the US on gateway and I'd say the UK consensus that we do see experimentation among young people, it's overwhelmingly among young people who have smoked or do smoke and there is no evidence of e-cigarettes taking young people who have recently smoked onto smoking. So that's pretty much what the evidence says. But with the US consensus it's very different where they're convinced that it does. The evidence doesn't support their assertions. (Official 1). 
It is not clear, given the international nature of the research on e-cigarettes, and science more generally, how it is possible for different consensuses to emerge on this on each side of the Atlantic, if evidence were indeed the decisive ingredient in forming consensus.

The attempt to create a consensus statement on the available evidence on e-cigarettes resulted in the publication of a report commissioned by PHE in August 2015, which contained the widely publicised claim that e-cigarettes are '95\% safer' than conventional cigarettes (McNeill et al., 2015a). The vehement criticism of the report, and the 95 figure in particular, by researchers and other actors in the field, appeared to undermine claims to there being an emerging consensus on the existing evidence on e-cigarettes (see, for example, McKee and Capewell, 2015b).

The idea of an emerging consensus is closely allied to the identification of a core group of scholars considered to be experts on the issue, and legitimate participants in the policy debates, whilst the credentials of those outside of this are called into question. This assignment of expertise reflected the disciplinary differences between those advocating harm reduction and precautionary approaches discussed above. As one researcher in the field commented:

And it's actually a relatively small number of people here who are not really tobacco experts. [...] But I think that my hypothesis is that there is a lot of tobacco control experts in this country. And they are almost all of pretty much the same view (Academic 2).

The issue of consensus was not just about winning the internal debates within public health but had clear implications for the ability of public health actors on all sides to influence government policy. The importance of consensus in influencing government policy on e-cigarettes was highlighted by respondents.

when everybody speaks the same tune and on the same evidence, they keep saying it and then it gets through. [...] So what evidence points out about that process is a lot of it is about consensus, ensuring you have consensus and most tobacco issues [...] are actually an incredibly difficult piece of legislation to get through. Nobody has really had the appetite for it in government, but by the same big cohort of health charities continually talking about it, the unified voice, that's what's ultimately shifted (Public Health NGO 3).

The issue of e-cigarettes has opened up significant divisions within the public health community with implications not just for e-cigarette policy, but for wider debates in tobacco control. Divisions within the public health community are clearly advantageous for the tobacco industry, whose objective is to avoid further curtailments of their ability to sell and market their products and 
their consumers' ability to use them. It distracts tobacco control advocates from other issues such as the expansion of generic packaging and undermines the unity of their approach on these issues. In this context it is unsurprising that public health actors are seeking to suture over divisions in their ranks and claim an emerging consensus not simply to influence e-cigarette policy to ensure that wider tobacco control objectives are not derailed. At the same time, it provides a clear rationale for why tobacco industry actors would seek to enter the e-cigarette market and attempt to influence these debates. As one NGO actor commented:

I think that plays into tobacco industry interests, because really, what's getting missed in this picture is the ongoing harm that tobacco does, and we need to not lose that, because I think the press is very keen on new things and shiny things, and techy things, and I think we're in real danger of losing the focus on the big problem of tobacco that remains (Public Health NGO 4).

It is clear then that the goal of consensus within the wider public health community is a key strategic device within the e-cigarette debates and an objective to be pursued. Whilst actors present this in terms of advancing the evidence base to the point where consensus emerges, leading to effective, evidence informed policies, it reveals an acute awareness of the argumentative power of consensus in advancing a particular policy agenda. The ability to claim consensus allows certain actors to offer government a clear, unified policy narrative while claiming the authority of the entire research community. In the context of the divisions emerging in the public health arena, there appears to be an attempt by actors broadly favourable to e-cigarettes, coalescing around PHE, to present their position on the issue as representing the consensus view of the entire tobacco control or public health community. Despite the claims of emerging consensus, the inferences to be drawn from existing studies appear to be interpreted in different ways by different policy actors.

\section{Discussion}

There is a strong culture of evidence-based policy-making in the UK, which dates back at least to the early years of the New Labour Government in the late 1990s and which is widely supported as an objective in the public health research and advocacy communities. Many policy debates in tobacco control and health policy focus on the evidence base underpinning specific proposals. The framing of the policy debates in evidentiary terms reflects not only the policy-making context in the UK, but also the academic and professional backgrounds from which the key participants emerge (smoking cessation and public health). Many of these actors are equipped with 
expertise in these disciplines which allows them to undertake complex and highly specialised forms of research which are of clear relevance to the issues at hand in tobacco control and public health policy debates.

Recent contributions to the literature on evidence-informed policy-making have highlighted the problematic nature of mainstream conceptions of evidence-based policy-making. The shift to the concept of evidence-informed policy-making and process driven accounts of evidence use reflect and acknowledge the fundamentally political and discursive nature of policy debates (Hawkins and Parkhurst, 2016, Greenhalgh and Russell, 2009, Majone, 1989). Decision-makers will be confronted with multiple framings of the key policy issues. Multiple bodies of evidence may be relevant to deciding on specific policy outcomes. What is seen to be the most relevant body of evidence will depend on the way in which the problem is constructed, which reflects in turn underlying values, ideologies and political priorities.

In the current e-cigarette debates, both sides point to evidence which supports their positions, but in keeping with many policy debates, overestimate the ability of evidence to resolve what are conflicts between different frames and political objectives, rather than facts (see Stone, 1997). The divisions which have emerged over e-cigarettes between colleagues who had successfully worked towards shared tobacco policy objectives for years, or even decades, is a key development in UK public health. Consensus amongst tobacco control advocates had been key to their success in changing social attitudes and policies on smoking. The recognition of this has led to attempts to suture together this ruptured unity under the banner of consensus. Attempts by some policy actors to claim consensus is emerging between actors, however, represents a political act designed to claim the authority associated with scientific consensus for a partial and contested framing of the issue and the policy agenda. It is also indicative of the assumptions which these policy actors make about the nature of the policy process and the role of evidence within it.

Both sides see the evidence supporting their position and view the disagreements of other actors as arising, not from an incommensurate framing of the policy problem, but from an unwillingness or an inability of their interlocutors to interpret the evidence they posit correctly. This may be due to incompetence, lack of specialism, or mendacity. The latter explanation is made more plausible - and more vehemently contested - given the prominence of the tobacco industry in the field, and the reputational damage which would arise from allegations of collusion with the industry. We argue, the disputes arise instead from a misrecognition of the fundamentally political nature of the policy process and the importance of issue framing in setting the parameters of policy debates, and thus the assessment of relevant bodies of evidence. Policy actors may legitimately differ in their 
recognition of the policy problem and the outcomes which policy makers should seek to bring about. Such disputes over the purpose of policy cannot be resolved solely by recourse to scientific studies. When other policy actors appear to 'ignore' the evidence they are actually framing the issue differently and looking at different bodies of evidence indicated by their issue framing. To return finally to Carol Weiss' schema: they think they are engaged in a rational process of evidence use but in fact it is political.

The limitations of this study are that it relies on a relatively limited range of interviewees and we were unable to speak to all relevant policy actors given the reluctance of some potential respondents to participate in the study. However, we were able to speak to a range of actors articulating very different positons on e-cigarettes from different professional standpoints. In addition, we were unable to map in a more nuanced way the full range of positions adopted by policy actors towards e-cigarettes. Inevitably some of those involved in the debates will not feel they fit into either 'camp' we identify. Despite this, the differing positions we identify have been prominently articulated in current policy debates and have played an important role in structuring wider debates within public health. As such, they are important to consider in the context of seeking to develop effective policies and also represent perhaps the greatest challenge in seeking consensus over regulatory approaches to e-cigarettes.

\section{Conclusion}

The acrimony surrounding current debates on e-cigarettes reflects a misrecognition amongst key policy actors about the nature of the policy process. From the perspective of interpretative policy analysis, policy actors are engaged in a dialogical process of argumentation and persuasion in which relevant research evidence plays an important role, but cannot serve as the definitive arbiter in disputes between different groups of actors who define the issues at stake - and thus the policy solutions which follow from these - in fundamentally different terms. The lens of interview respondents in this study is that of the rational-linear tradition of evidence-based medicine extended to public health. It is unsurprising that policy actors focused on the analysis of empirical data from which to judge the effectiveness of certain interventions, would not be inclined to engage with issues of policy framing, or to question whether multiple definitions of 'the policy problem' are possible. They may find the very notion of multiple problem definitions unsatisfactory, or in need of more precise definition to remove ambiguity. Nevertheless, the insights brought to bear on the ecigarette debates from the perspective of policy studies offers a plausible explanation of the current policy disputes between the advocates of 'harm reduction' and 'precautionary' approaches. In 
addition, approaches to the policy process which draw on ideas of 'frame reflection' as a means of overcoming intractable policy disputes may be informative in reducing the current acrimony between some public health actors and may facilitate more effective, co-ordinated policy approaches by these actors in ways similar to their effective engagement in previous tobacco control debates. 


\section{References}

ABRAMS ET AL., 2014, Statement from specialists in nicotine science and public health policy [Online]. Available: http://www.webcitation.org/6ULpMDtvW [Accessed 8 August 2014].

ADKISON, S E, O'CONNOR, R J, BANSAL-TRAVERS, M, HYLAND, A, BORLAND, R, YONG, H-H, CUMMINGS, K M, MCNEILL, A, THRASHER, J F \& HAMMOND, D, 2013, Electronic nicotine delivery systems: international tobacco control four-country survey. American journal of preventive medicine, 44, 207-215.

AKTAN ET AL., 2014, 129 public health and medical authorities from 31 countries write WHO DG Chan urging evidence-based approach to ecigs [Online]. Available: http://www.webcitation.org/6ULpRXpPJ [Accessed 8 August 2014].

ASH, 2016, Ash Facts at a Glance: Smoking Statistics June 2016 [Online]. ASH UK. Available: http://www.ash.org.uk/files/documents/ASH 93.pdf [Accessed 12 December 2016].

BAULD, L, ANGUS, K \& DE, A M, 2014, E-cigarette uptake and marketing: A report commissioned by Public Health England. Public Health England. Public Health England.

BAULD, L, MCNEILL, A, HAJEK, P, BRITTON, J \& DOCKRELL, M, 2016, E-cigarette use in public places: striking the right balance. Tobacco Control, tobaccocontrol-2016-053357.

BOSWELL, C, 2009, The political uses of expert knowledge: Immigration policy and social research, Cambridge University Press.

BRITISH AMERICAN TOBACCO, 2013, A Focus on Harm reuction: Why it Matters [Online]. Available: http://www.webcitation.org/6ULgu6003 [Accessed 6 November 2013 2013].

BRITISH AMERICAN TOBACCO, 2014, Harm reduction [Online]. Available: http://www.webcitation.org/6UUk3uia1 [Accessed 1 December 2014].

BRITTON, J \& BOGDANOVICA, I, 2014, Electronic Cigarettes. A Report Commissioned by Public Health England, 30pp. London, UK: Public Health England.

BUSH, A M, HOLSINGER JR, J W \& PRYBIL, L D, 2016, Employing the Precautionary Principle to Evaluate the Use of E-Cigarettes. Frontiers in public health, 4.

DAVOUDI, S, 2006, Evidence-based planning: rhetoric and reality. disP-The Planning Review, 42, 14 24.

ELLEN, M E, LÉON, G, BOUCHARD, G, OUIMET, M, GRIMSHAW, J M \& LAVIS, J N, 2014, Barriers, facilitators and views about next steps to implementing supports for evidence-informed decision-making in health systems: a qualitative study. Implementation Science, 9, 179.

FARSALINOS, K E \& LE HOUEZEC, J, 2015, Regulation in the face of uncertainty: the evidence on electronic nicotine delivery systems (e-cigarettes). Risk management and healthcare policy, 8, 157.

FISCHER, F, 2012, The argumentative turn revisited: Public policy as communicative practice, Duke University Press.

GILMORE, A B \& PEETERS, S, 2013, Understanding corporations to inform public health policy: the example of tobacco industry interests in harm reduction and reduced risk products. The Lancet, 382, S14.

GNEITING, U, 2015, From global agenda-setting to domestic implementation: successes and challenges of the global health network on tobacco control. Health Policy and Planning, czv001.

GORNALL, J, 2015, Why e-cigarettes are dividing the public health community.

GRANA, R, BENOWITZ, N \& GLANTZ, S A, 2014a, E-cigarettes a scientific review. Circulation, 129, $1972-1986$.

GRANA, R A, LING, P M, BENOWITZ, N \& GLANTZ, S, 2014b, Electronic Cigarettes. Circulation, 129, e490-e492.

GREENHALGH, T \& RUSSELL, J, 2006, Reframing evidence synthesis as rhetorical action in the policy making drama. Healthcare policy = Politiques de santé, 1, 34-42. 
GREENHALGH, T \& RUSSELL, J, 2009, Evidence-based policymaking: a critique. Perspectives in Biology and Medicine, 52, 304-318.

GREENHALGH, T \& WIERINGA, S, 2011, Is it time to drop the 'knowledge translation'metaphor? A critical literature review. JRSM, 104, 501-509.

HAWKINS, B \& CASSIDY, R, 2016, Interviewing Key Informants from the Corporate Sector. Researching Corporations and Global Health Governance: An Interdisciplinary Guide, 127.

HAWKINS, B \& PARKHURST, J, 2016, The 'good governance' of evidence in health policy. Evidence \& Policy: A Journal of Research, Debate and Practice.

HURT, R D, EBBERT, J O, MUGGLI, M E, LOCKHART, N J \& ROBERTSON, C R, 2009, Open doorway to truth: legacy of the Minnesota tobacco trial. Mayo Clinic proceedings. Mayo Clinic, 84, 44656.

KALKHORAN, S \& GLANTZ, S A, 2016, E-cigarettes and smoking cessation in real-world and clinical settings: a systematic review and meta-analysis. The Lancet Respiratory Medicine, 4, 116128.

KOON, A D, HAWKINS, B \& MAYHEW, S H, 2016, Framing and the health policy process: a scoping review. Health policy and planning, czv128.

LAVIS, J N, OXMAN, A D, LEWIN, S \& FRETHEIM, A, 2009, SUPPORT Tools for evidence-informed health Policymaking (STP). Health research policy and systems / BioMed Central, 7 Suppl 1, I1-I1.

MAJONE, G, 1989, Evidence, argument, and persuasion in the policy process, Yale University Press.

MCKEE, M \& CAPEWELL, S, 2015a, Electronic cigarettes: we need evidence, not opinions. The Lancet, 386, 1239.

MCKEE, M \& CAPEWELL, S, 2015b, Evidence about electronic cigarettes: a foundation built on rock or sand?

MCNEILL, A, BROSE, L, CALDER, R, HITCHMAN, S, HAJEK, P \& MCROBBIE, H, 2015a, E-cigarettes: an evidence update. Public Health England, 3.

MCNEILL, A, BROSE, L S, CALDER, R, HITCHMAN, S C, HAJEK, P \& MCROBBIE, H, 2015b, E-cigarettes: the need for clear communication on relative risks. The Lancet, 386, 1237.

OLIVER, K, LORENC, T \& INNVAER, S, 2014, New directions in evidence-based policy research: a critical analysis of the literature. Health Research Policy and Systems, 12, 1.

PARKHURST, J O \& ABEYSINGHE, S, 2016, What Constitutes "Good" Evidence for Public Health and Social Policy-making? From Hierarchies to Appropriateness. Social Epistemology, 1-15.

RADAELLI, C M, 2005, Diffusion without convergence: how political context shapes the adoption of regulatory impact assessment. Journal of european public policy, 12, 924-943.

REIN, M \& SCHÖN, D, 1994, Frame Reflection. Towards the resolution of intractable policy controversies. New York: Basic Books.

RUBIN, H J \& RUBIN, I S, 2011, Qualitative interviewing: The art of hearing data, Sage.

RUSSELL, J, GREENHALGH, T, BYRNE, E \& MCDONNELL, J, 2008, Recognizing rhetoric in health care policy analysis. Journal of health services research \& policy, 13, 40-6.

SMITH, K, 2013, Beyond evidence based policy in public health: the interplay of ideas, Palgrave Macmillan.

STEVENS, A, 2007, Survival of the ideas that fit: an evolutionary analogy for the use of evidence in policy. Social Policy and Society, 6, 25-35.

STONE, D A, 1989, Causal stories and the formation of policy agendas. Political science quarterly, 104, 281-300.

STONE, D A, 1997, Policy paradox: The art of political decision making, WW Norton New York.

THAMLIKITKUL, V, 2006, Bridging the gap between knowledge and action for health: case studies. Bulletin of the World Health Organization, 84, 603-607.

TOBACCO TACTICS, 2014, E-cigarettes [Online]. Tobacco Tactics. Available: http://www.tobaccotactics.org/index.php/E-cigarettes [Accessed 19 Septmeber 2014]. 
WEISS, $\mathrm{C} \mathrm{H}, 1979$, The many meanings of research utilization. Public administration review, 39, 426431.

WIPFLI, H, 2015, The Global War on Tobacco, Baltimore, ML, Johns Hopkins University Press. 